\title{
Immobilization of mercury in contaminated soils through the use of new carbon foam amendments
}

\author{
I. Janeiro-Tato ${ }^{1}$, M. A. Lopez-Anton ${ }^{1 *} \mathbb{B}$, D. Baragaño ${ }^{2}$, C. Antuña-Nieto ${ }^{1}$, E. Rodríguez ${ }^{1}$, A. I. Peláez ${ }^{3,4}$, \\ J. R. Gallego ${ }^{2}$ and M. R. Martínez-Tarazona ${ }^{1}$
}

\begin{abstract}
Background: Mercury $(\mathrm{Hg})$ is recognized as one of the 10 most toxic elements in nature and is much more persistent in soils than in other environmental compartments. However, an effective, environmentally friendly, economical, and large-scale applicable technology for the remediation of soils contaminated by Hg has not yet been established. This study evaluates the feasibility of a new carbon foam-based product for the remediation of three soils contaminated with $\mathrm{Hg}$, and infers the mobilization or immobilization mechanism through a detailed study of $\mathrm{Hg}$ speciation.

Results: Soil treatment with carbon foams, one of them impregnated with goethite, reduced $\mathrm{Hg}$ availability by 75-100\%. The proportion of mercury associated to humic acids ( $\mathrm{Hg}-\mathrm{HA}$ ) determined the mobility and the availability of $\mathrm{Hg}$ when soils were treated with carbon foams. The drop of $\mathrm{pH}$ promotes changes in the structure of $\mathrm{HA}$, a consequence of which is that $\mathrm{Hg}-\mathrm{HA}$ becomes part of the unavailable fraction of the soil along with $\mathrm{HgS}$. The carbon foam impregnated with goethite did not mobilize Fe as occurred with zero valence iron nanoparticles. The presence of acidic groups on the surface of the foam (carboxyl, quinone and phenolic groups) can strongly improve the binding of metal cations, enhancing Fe immobilization.

Conclusions: A novel carbon foam-based amendment was efficient in immobilizing $\mathrm{Hg}$ in all the soils studied. The carbon foam impregnated with goethite, in addition to not mobilizing $\mathrm{Fe}$, had the additional advantage of its low effect on the electrical conductivity of the soil. This novel approach could be considered as a potential amendment for other industrial and/or abandoned mining areas contaminated with $\mathrm{Hg}$ and/or other metal(loid)s.
\end{abstract}

Keywords: Bioavailability, Soil remediation, Carbon foams, Goethite, Mercury speciation

\section{Background}

Mercury is a recognized neurotoxic metal that can seriously affect health, especially in children and pregnant women. In 2017, an international agreement of expected compliance was finally reached in the UN Minamata Convention to permanently solve the problem of $\mathrm{Hg}$ pollution, which considers aspects such as mercury waste, polluted sites and industrial emissions

\footnotetext{
*Correspondence: marian@incar.csic.es

${ }^{1}$ Instituto de Ciencia Y Tecnología del Carbono, INCAR-CSIC, C/ Francisco

Pintado Fe, 26, 33011 Oviedo, Spain

Full list of author information is available at the end of the article
}

[1]. This agreement highlights the necessity of innovative approaches and technology transfer in relation to $\mathrm{Hg}$ management.

According to the United Nations Environment Programme (UNEP) [2], in 2015, approximately 2000 tons of $\mathrm{Hg}$ were emitted into the air from anthropogenic sources. Reemission from soils and oceans, which are acting as reservoirs, has led to higher levels of atmospheric $\mathrm{Hg}$ concentration. Moreover, $\mathrm{Hg}$ is much more persistent in soils than in other environmental compartments [3].

Technologies for remediation of Hg-contaminated soils include, but are not limited to, soil washing, stabilization/

\section{Springer Open}

(c) The Author(s) 2021. Open Access This article is licensed under a Creative Commons Attribution 4.0 International License, which permits use, sharing, adaptation, distribution and reproduction in any medium or format, as long as you give appropriate credit to the original author(s) and the source, provide a link to the Creative Commons licence, and indicate if changes were made. The images or other third party material in this article are included in the article's Creative Commons licence, unless indicated otherwise in a credit line to the material. If material is not included in the article's Creative Commons licence and your intended use is not permitted by statutory regulation or exceeds the permitted use, you will need to obtain permission directly from the copyright holder. To view a copy of this licence, visit http://creativecommons.org/licenses/by/4.0/. 
solidification, nanotechnology, thermal treatment, and biological treatments such as phytoremediation and bioremediation [4-6]. The effectiveness of each technology depends on several soil characteristics, so a thorough site assessment must be performed prior to the application of any technique. Nowadays, there is an increasing interest in the development of low-cost, in situ and environmentally friendly technologies to replace traditional remediation practices, such as thermal treatment and soil washing [7]. Natural-based solutions (NBS) [8] require the use of effective and green technologies such as enhanced thermal treatment [9], application of $\mathrm{Hg}$ volatilizing bacteria [10] and certain amendments for $\mathrm{Hg}$ immobilization [11].

In situ physical-chemical $\mathrm{Hg}$ immobilization techniques can minimize health risks by reducing the bioavailability of $\mathrm{Hg}$ [12], while improving soil properties [13]. For instance, the application of a sulfur-modified biochar reduced $99.3 \%$ of freely available $\mathrm{Hg}$ in toxicity characterization leaching procedure (TCLP) leachates [14]. The use of nanoparticles has also been found to be effective for the immobilization of $\mathrm{Hg}$ and other heavy metal(loid)s [11, 15, 16]. A significant decrease in $\mathrm{Hg}$ and As availability was found after the application of zero valence iron nanoparticles (nZVI) to contaminated soils [11]. Column tests of sediment treatment with a $0.5 \mathrm{~g} / \mathrm{L}$ FeS nanoparticles suspension showed a $\mathrm{Hg}$ reduction of $>77 \%$ in the TCLP leachability [15]. Selenium nanoparticles turned out to be effective for $\mathrm{Hg}^{0}$ immobilization [16]. However, the fate and transport of nanoparticles in the environment and their effect on human health are not well established yet [17]. Although, as previously mentioned, different amendments showed high efficiency to immobilize $\mathrm{Hg}$ and immobilization technology has been recognized as the most economical and easily accessible method for the remediation of contaminated soils [18], this technology is still under development, new materials are emerging [19] and the mechanisms of $\mathrm{Hg}$ immobilization are not fully understood. With these objectives in mind, this study proposes the development of a new amendment that combines the good results of $\mathrm{Hg}$ immobilization achieved with other materials [14] and with $\mathrm{Fe}$ nanoparticles [11], while avoiding possible environmental risks caused with the latter [17].

The mobility of $\mathrm{Hg}$ depends on its chemical speciation, which is a function of several soil parameters and their interactions. In addition, information about the mercury species present in the soils is essential to establish an effective remediation methodology. Mercury speciation analyses require very sensitive techniques that preserve the integrity of the species during sampling and over the entire analytical procedure. The most common methods to determine $\mathrm{Hg}$ species in solids can be classified as: i) indirect methods, which are sequential chemical extraction methods [20], and ii) direct methods, such as X-ray absorption spectroscopy (EXAFS or XANES) [21] and programmed thermal desorption [22]. The main drawback of sequential extraction is the impossibility of distinguishing all $\mathrm{Hg}$ species as they are selectively distributed by groups. EXAFS and XANES, on the other hand, present the disadvantage of high detection limits, which make them useful only for very highly contaminated samples; in addition, they require complex equipment with difficult access. Programmed thermal desorption does not require the use of reagents, is direct and fast and has very low detection limits; in some cases, however, its selectivity is limited by peaks overlapping, which prevents the reliable identification of some $\mathrm{Hg}$ species. In the present work, direct and indirect methods are used in a complementary manner, in order to identify mercury species in soils, before and after being treated in situ with amendments.

Carbon foams are a new generation of materials with enormous application potential [23]. They are ultralight carbonaceous materials with high adsorption capacity that can favor the nanodispersion of iron species on their surface, when they are provided with microporous texture. Furthermore, these materials can be modified for an improved performance. For example, if loaded with goethite, which has a structure more prone to complex with cations than other Fe compounds [24], they could achieve a more efficient immobilization of contaminants such as As [25], reducing the risks associated with the application of alternative Fe-based amendments. Consequently, in this work, the development of a carbon foam impregnated with goethite is contemplated as an attractive and novel solution to be used as a soil amendment for multi-contaminated soils.

This study provides a demonstration that carbon foams impregnated with goethite can be used as a soil amendment for $\mathrm{Hg}$ immobilization. Three contaminated soils from industrial areas were tested to evaluate the effects of the new carbon foam amendments on $\mathrm{pH}$, electrical conductivity (EC) and the availability of Fe, and to understand the mobility of $\mathrm{Hg}$ in soils through an in-depth study of the $\mathrm{Hg}$ speciation in the untreated and treated soils.

\section{Experimental \\ Soil samples}

Three samples of mercury-contaminated soils were chosen for this study. The locations and the different characteristics of these soils have been previously reported [26-28]. In brief, they were taken from two abandoned $\mathrm{Hg}$ mining-metallurgy sites ( $\mathrm{S}$ and $\mathrm{T}$ soils) and an industrial area (A soil). Soil S was sampled in La Soterraña 
mine, and it is classified as sandy loam, revealing slightly alkaline $\mathrm{pH}[26]$. The other mining soil (T), was taken in El Terronal mine. This soil is also slightly alkaline and it reveals a silt loam texture [27]. Mercury mining and processing activities are generally characterized by an abundance of $\mathrm{Hg}$ in the emissions and waste generated, thus both studied mining soils are appropriate for this work. Finally, the industrial soil (A) was taken in the surrounding of a $\mathrm{Zn}$ smelter located in Avilés (north Spain). This third soil is also alkaline, but the texture is clearly sandy [28]. The influence of multiple pollution sources, such as metallurgical dust, slags, and other wastes disposed in this site, has a dramatic effect on quality of soil.

\section{Soil amendments}

The following materials were used as amendments:

- nZVI. These nanoparticles were supplied by NANO IRON s.r.o (Czech Republic) as NANOFER 25S. The suspension contains $14-18 \%$ of $\mathrm{Fe}(0)$ and $2-6 \%$ of iron oxide. The suspension is alkaline with a $\mathrm{pH}$ of 9.5-11.5.

- Carbon foam (CF). The methodology followed to prepare a microporous carbon foam using a coal as precursor has been described elsewhere [29]. In brief, a green carbon foam is synthetized from a mixture of coal and an activation agent $\left(\mathrm{ZnCl}_{2}\right)$ in a closed reactor, at the temperature of maximum fluidity of the coal $\left(450{ }^{\circ} \mathrm{C}\right)$, and in an inert (Ar) atmosphere. The resulting green foam is carbonized under an $\mathrm{Ar}$ flow of $100 \mathrm{~mL} \mathrm{~min}{ }^{-1}$, at $500{ }^{\circ} \mathrm{C}$ and washed to remove inorganic salts. The final carbon foam was ground and sieved in the range of $0.2-0.5 \mathrm{~mm}$.

- Carbon foam impregnated with goethite (CFGo). The carbon foam previously obtained, was impregnated with a solution of $\mathrm{FeSO}_{4} \cdot 7 \mathrm{H}_{2} \mathrm{O}$ and $\mathrm{CH}_{3} \mathrm{COONa}$ in water, with the following proportions: $1.5 \mathrm{~g} \mathrm{CF} /$ $0,28 \mathrm{~g} \mathrm{FeSO}_{4} / 0,4 \mathrm{~g} \mathrm{CH}_{3} \mathrm{COONa} / 5 \mathrm{~mL} \mathrm{H}_{2} \mathrm{O}$. The suspension of the carbon foam was shacked in an ultrasonic bath for $1 \mathrm{~h}$ at $40 \mathrm{kHz}$ and then heated under reflux for $2 \mathrm{~h}$. After cooling to room temperature, the solution was filtered and the solid dried at $60{ }^{\circ} \mathrm{C}$ for $4 \mathrm{~h}$. This treatment results in the formation of goethite $(\mathrm{FeO}(\mathrm{OH}))$ on the surface of the carbon foam.

\section{Soil analysis and carbon foam characterization}

Electrical conductivity (EC) and $\mathrm{pH}$ were measured to evaluate the influence of the amendment application on soil properties in a suspension of soil $(1 \mathrm{~g})$ and Milli- $\mathrm{Q}$ water $(2.5 \mathrm{~mL})$. The functional groups present on the surface of the carbon foams were identified by temperature programmed desorption (TPD): the oxygenated groups decompose mainly into $\mathrm{CO}$ and $\mathrm{CO}_{2}$, which are released at temperatures that can be related to the type of functional group of origin [30,31]. The distribution and particle size of iron on the surface of the carbon foam were studied by scanning electron microscopy (SEM), whereas the crystalline structure was examined by X-ray diffraction (XRD). The analysis of $\mathrm{Hg}$ in all the solid and liquid samples was directly determined using an automatic mercury analyzer AMA 254.

\section{Soil treatment}

Subsamples of polluted soils $(20 \mathrm{~g})$ were treated in $50-\mathrm{mL}$ vials maintaining the proportion of $20 \%$ of amendment and $80 \%$ of soil, i.e., $16 \mathrm{~g}$ soil and $4 \mathrm{~g}$ carbon foam. In the case of nZVI suspension, the proportion was $2 \%(\mathrm{w} / \mathrm{w})$, a cost-effective dose according to previous studies carried by the authors $[25,32]$. Deionized water was added to the vials to achieve water holding capacity of the soil. The vials were shaken on an orbital shaker at $170 \mathrm{rpm}$ for $72 \mathrm{~h}$. Finally, the treated soils were air dried.

\section{Leaching test}

The mobility of $\mathrm{Hg}$ in the untreated and treated soils was determined by TCLP tests following the USEPA Method 1311 (1992). The leaching tests were carried out in 50-mL vials using $1 \mathrm{~g}$ of sample and $20 \mathrm{~mL}$ of $\mathrm{CH}_{3} \mathrm{COOH} /$ $\mathrm{NaOH}$ at $\mathrm{pH} 4.93 \pm 0.05$. The samples were placed on an orbital shaker at $170 \mathrm{rpm}$ for $18 \mathrm{~h}$. Then, the liquid was separated from the solid by centrifugation $(4000 \mathrm{rpm}$ for $15 \mathrm{~min}$ ), filtered and preserved at $4{ }^{\circ} \mathrm{C}$. The liquids were then analyzed for $\mathrm{Hg}$ as described in Sect. 2.3.

\section{$\mathrm{Hg}$ speciation and sequential extraction}

The potential mobility and availability of $\mathrm{Hg}$ in soil samples were also evaluated by two sequential extraction procedures: the Tessier method [33] and a simplified USEPA Method 3200 [34] that is specific for mercury species. The Tessier and USEPA 3200 methods consist of five and three sequential extraction steps, respectively, which yield five and three $\mathrm{Hg}$ fractions, as a function of each species solubility in different solvents. The following fractions are obtained with the Tessier method: exchangeable (EX); bound to carbonates (CB); bound to $\mathrm{Fe}-\mathrm{Mn}$ oxides (OX); bound to organic matter $(\mathrm{OM})$ and residual (RS). In turn, the USEPA Method 3200 provides: mobile $\mathrm{Hg}$ (M), semi-mobile $\mathrm{Hg}(\mathrm{SM})$ and non-mobile $\mathrm{Hg}(\mathrm{NM}) . \mathrm{Hg}$ concentrations were measured in the extracts using the AMA 254 analyser.

The study was completed with the identification of mercury species in the untreated and treated soils directly using a mercury temperature programmed desorption (HgTPD) device [35]. The device, previously 
described [36], consists of a temperature-programed furnace coupled to a PYRO 915 furnace from LUMEX and a continuous mercury analyzer (RA-915). Desorption profiles are obtained by heating the sample at a rate of $50{ }^{\circ} \mathrm{C} \mathrm{min}{ }^{-1}$. The different desorption peaks obtained are assigned to each mercury species using the reference database made with mercury compounds. The compounds used in this work as reference were mercury bound to humic acids ( $\mathrm{Hg}-\mathrm{HA})$ and $\mathrm{HgS}$, as they are the most likely species to be present in soil samples, as well as other species that can possibly be present, such as $\mathrm{Hg}^{0}, \mathrm{HgO}$ and $\mathrm{HgCl}_{2}$.

\section{Statistical analysis}

Statistical analyses were carried out using the SPSS 24.0 program. Analysis of variance (ANOVA) and test of homogeneity of variance were performed using LSD's and Dunnett's T3 tests.

Table 1 Electrical conductivity, $\mathrm{pH}$ and $\mathrm{Hg}$ content in the soils and carbon foams studied

\begin{tabular}{|c|c|c|c|c|}
\hline & $\mathrm{pH}$ & $\mathrm{EC}\left(\mathrm{dS} \mathrm{m}^{-1}\right)$ & $\mathrm{Hg}\left(\mathrm{mg} \mathrm{kg}^{-1}\right)$ & Soil texture \\
\hline A & $7.8 \pm 0.0$ & $0.18 \pm 0.00$ & $18.0 \pm 0.9$ & Sandy [28] \\
\hline S & $7.7 \pm 0.0$ & $0.46 \pm 0.00$ & $1251 \pm 5$ & Sandy loam [26] \\
\hline $\mathrm{T}$ & $6.8 \pm 0.0$ & $0.15 \pm 0.00$ & $1361 \pm 94$ & Silt loam [27] \\
\hline$C F$ & $2.7 \pm 0.0$ & $1.17 \pm 0.02$ & $<\mathrm{DL}$ & \\
\hline CFGo & $4.2 \pm 0.0$ & $0.76 \pm 0.00$ & $<\mathrm{DL}$ & \\
\hline
\end{tabular}

$D L$ detection limit, CF carbon foam, CFGo carbon foam impregnated with goethite

\section{Results and discussion}

\section{Soil and carbon foam characterization}

The electrical conductivity (EC), $\mathrm{pH}$, and $\mathrm{Hg}$ content in the soils (A, S and T) and carbon foams (CF and CFGo) are shown in Table 1 . The soil texture is also shown in Table 1 . The three soils showed $\mathrm{pH}$ values ranging from 6.8 to 7.8. The remarkable high concentrations of $\mathrm{Hg}$ in $\mathrm{S}$ and $\mathrm{T}$ soils exceed the maximum levels permitted by regional [37] and international regulations [38, 39]. In the case of the A soil, the mercury concentration is lower than the limit set for industrial soils, although it is higher than that of soils reserved for recreational purposes, residential or other uses. Therefore, these soils pose a high environmental risk.

Figure 1 shows two SEM images of the carbon foam before and after impregnation with goethite $(\mathrm{FeO}(\mathrm{OH}))$. Among other properties, these carbon foams possess a combined macro- and microporous structure that favors the adsorption process (Additional file 1: Table S1). The analysis of CFGo by SEM (Fig. 1b) and $\mathrm{XRD}$ (Additional file 1: Figure $\mathrm{S} 1$ ) revealed the presence of $\mathrm{FeO}(\mathrm{OH})$ in the form of nanoneedles homogeneously distributed on the surface of the carbon foam. The impregnation with $\mathrm{FeO}(\mathrm{OH})$ moderated the carbon foam original $\mathrm{pH}$ and $\mathrm{EC}$ values (Table 1).

The analysis by TPD showed a greater number of phenol and/or ether groups, represented by the peak arising at $600-800{ }^{\circ} \mathrm{C}$ in the $\mathrm{CO}$ curve, and carbonyl and quinone groups (desorption peak around $800-900{ }^{\circ} \mathrm{C}$ ) in CFGo than in non-impregnated CF (Additional file 1: Figure S2). The presence of carboxylic acid-type groups
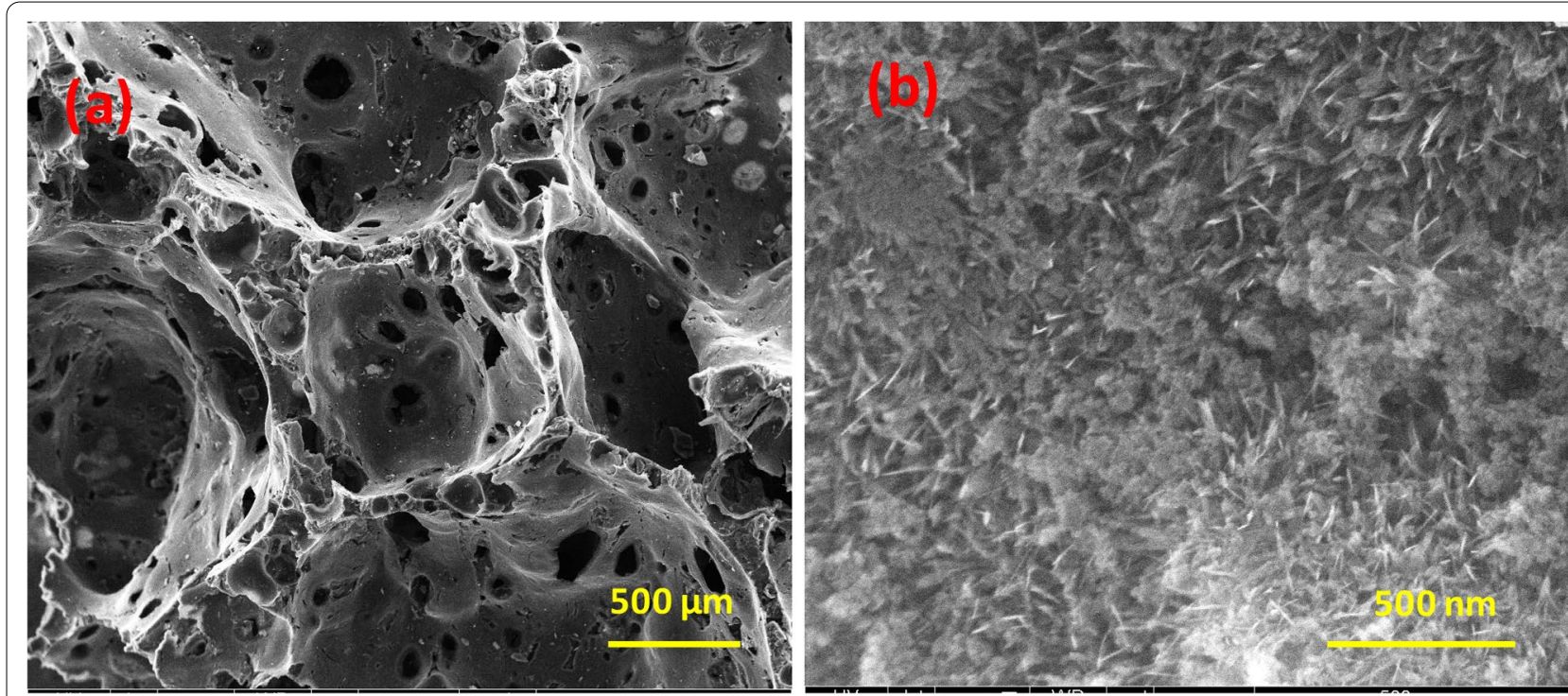

Fig. 1 SEM images of $\mathbf{a}$ CF and $\mathbf{b}$ CFGo 
was also observed, according to the desorption of $\mathrm{CO}_{2}$ around $200-400{ }^{\circ} \mathrm{C}$ (Additional file 1: Figure S2).

\section{Evaluation of $\mathrm{Hg}$ mobility}

Figure 2 shows the results of TCLP tests for soils before and after the treatment with nZVI, CF and CFGo. The three treatments reduced $\mathrm{Hg}$ leachability except for $\mathrm{A}$ soil treated with nZVI. This exception is likely due to the pH increase after nZVI treatment (Fig. 2a), since it is well known that $\mathrm{pH}$ is one of the most important factors affecting $\mathrm{Hg}$ mobility [40, 41].

It is generally assumed that the retention of $\mathrm{Hg}$ by nZVI is due to its chemical reduction and precipitation. The interaction between $\mathrm{Hg}$ and $\mathrm{Fe}$ has been observed within the nanoparticles and reduction mechanism of $\mathrm{Hg}^{2+}$ to $\mathrm{Hg}^{0}$ is suggested [42]. This process would be favored by the different standard redox potential of $\mathrm{Hg}(\mathrm{E} 0=0.86 \mathrm{~V})$ and $\mathrm{Fe}(\mathrm{E} 0=-0.44 \mathrm{~V})$, which makes $\mathrm{Hg}$ reduction thermodynamically favorable $(\Delta \mathrm{E}(0)=1.30 \mathrm{~V})$ [42]. In the case of the treatments with carbon foams, even in the absence of goethite, the leachability of $\mathrm{Hg}$ is reduced in all soils and $\mathrm{Hg}$ concentration drops below the detection limits of the automatic mercury analyzer AMA 254 in the case of soil A. It should be taken into account the role that dissolved organic matter plays in the adsorption of $\mathrm{Hg}$ by solid sorbents in aqueous phase and that it could justify the differences observed in the soil studied (Fig. 2).
In fact, several studies have found that an increase in dissolved organic matter can decrease $\mathrm{Hg}$ adsorption by activated carbons and other carbonaceous materials [43, 44], due to a competitive reaction between $\mathrm{Hg}(\mathrm{II})$ and the dissolved organic matter. Although it is beyond the scope of this study, partition coefficients and adsorption capacities should be taking into account, considering the specific characteristics of each site to be remedied by carbon foams. With the aim of understanding the retention of $\mathrm{Hg}$ by both carbon foams, a detailed study of $\mathrm{Hg}$ speciation was carried out with these materials.

\section{Evaluation of $\mathrm{Hg}$ speciation.}

The analysis of $\mathrm{Hg}$ speciation by HgTPD (Fig. 3) revealed that the main mercury species present before and after treatment with both carbon foams were $\mathrm{Hg}-\mathrm{HA}$ and $\mathrm{HgS}$, whose range of decomposition is from 100 to $300^{\circ} \mathrm{C}$ according to mercury standard profiles (Fig. 3d). However, some differences are observed in the profiles depending on the soil and the amendment.

When the soils are treated with the carbon foams the profiles are wider and have maximum desorption peaks at temperatures slightly higher than the untreated soils, suggesting a change of mercury speciation derived from the treatment. Additional file 1: Figure S3 shows the deconvolution of the thermal profiles for the original soils and after being treated with the carbon foam

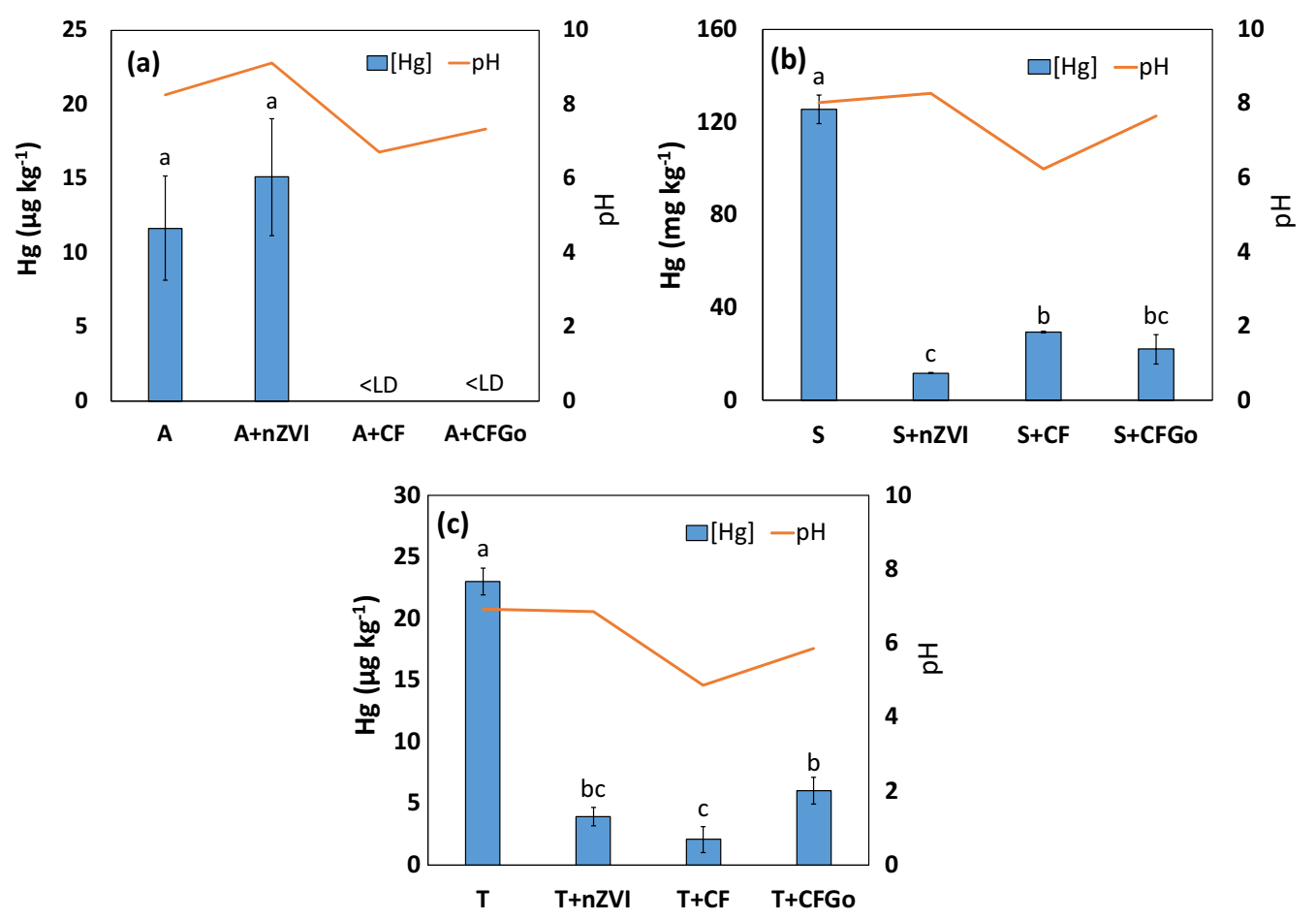

Fig. 2 Mercury concentration and pH in TCLP extracts with the three treatments applied to a A soil, $\mathbf{b} \mathrm{S}$ soil and $\mathbf{c} T$ soil 

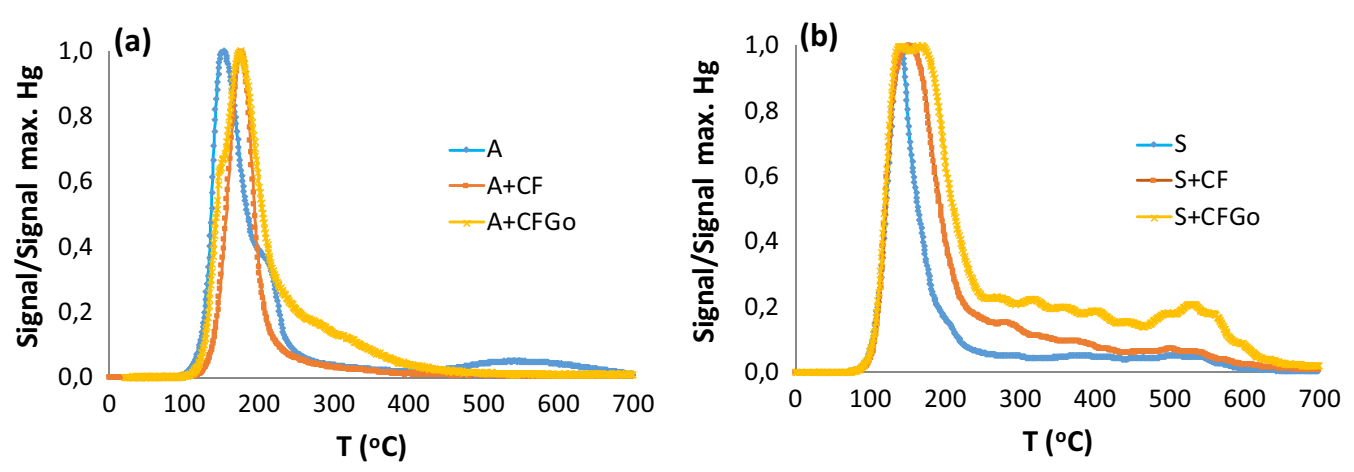

(c)
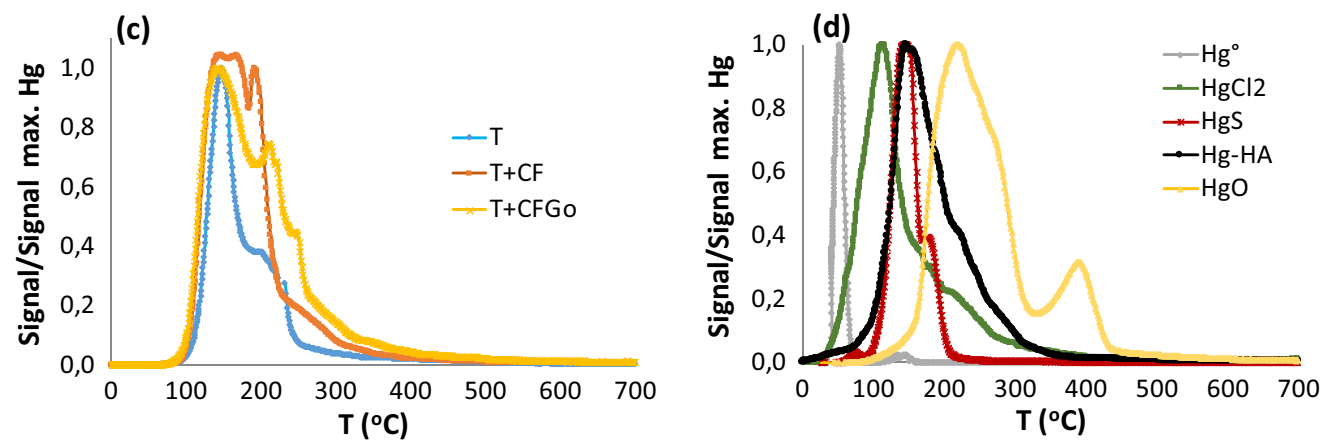

Fig. 3 Mercury thermal profiles of soils before and after treatment with the carbon foams for a A soil, $\mathbf{b} \mathrm{S}$ soil and $\mathbf{c} T$ soil, and $\mathbf{d}$ mercury pure compounds $\left(\mathrm{Hg}^{0}, \mathrm{HgCl}_{2}, \mathrm{HgS}, \mathrm{Hg}-\mathrm{HA}\right.$ and $\left.\mathrm{HgO}\right)$

impregnated with goethite. The overlapping of peaks corresponding to the main mercury species present in the raw soils, $\mathrm{HgS}$ and $\mathrm{Hg}-\mathrm{HA}$, are clearly observed. However, the distribution of these mercury species is different in the soils treated with CFGo (Additional file 1: Figure S3). The deconvolution of the desorption profile shows a slight shift in the second peak (green line) towards higher desorption temperatures in the soils treated with CFGo, suggesting the presence of stable $\mathrm{Hg}$ compounds such as $\mathrm{Hg}-\mathrm{HA}$ or $\mathrm{HgS}$. It should also be noted that $\mathrm{HgS}$ thermal profiles tend to have more standard deviation than other mercury species due to the different sizes of cinnabar crystals, which can vary depending on the soils. This fact is also reflected in the thermal profile of the soil (Additional file 1: Figure S3). Humic acids, one of the main components of soil organic matter, contain different functional groups. The complex structure of HA is dynamically dependent on environmental conditions such as $\mathrm{pH}$ or ionic strength, which determine the mobility of certain contaminants and trace metals. HA contains different size fractions with different mobility that affects the bioavailability of pollutants in different ways [41, 45]. Alkaline conditions were found to promote the disaggregation of HA particles, causing a greater mobility of pollutants [41]. This suggests that the very low $\mathrm{Hg}$ leachability observed when soils are treated with the carbon foam (Fig. 2) is a consequence of the decrease in $\mathrm{pH}$ values (Fig. 2), which leads to a change in the HA structure and a concomitant variation of $\mathrm{Hg}-\mathrm{HA}$ mobility.

Because HgTPD provides information on thermally related binding strength but does not estimate the mobility of $\mathrm{Hg}$ in the liquid phase, a speciation study in soils was carried out using two sequential extraction methods to confirm the proposed mechanism. Figure 4 shows the results obtained by the USEPA Method 3200 (left column) and the Tessier method (right column), in the untreated and treated soils.

Although it is well known that sequential extraction methods have as their main drawback the lack of selectivity and efficiency of each step of the procedure [46], the results showed that most of the mercury in the original and treated soils was extracted from the SM fraction (Fig. 4), which is consistent with the occurrence of mercury in $\mathrm{Hg}^{2+}$ complexes or amalgamates [33]. Mercury is also found in the NM fraction in the form of mercury stable compounds like $\mathrm{HgS}$ in all the soils. It is noteworthy that semi-mobile $\mathrm{Hg}$ decreased in soils after being treated with carbon foams, while non-mobile $\mathrm{Hg}$ increased, which implies lower leachability in treated soils (Fig. 2). These results agree with those inferred by the study carried out by HgTPD, which reflected a change in the 

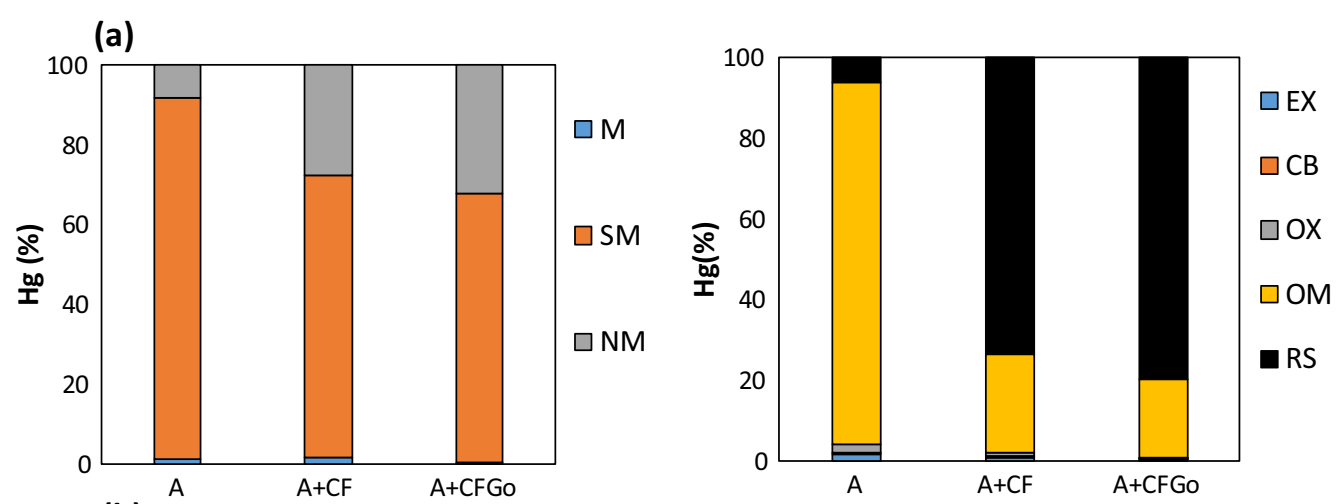

(b)
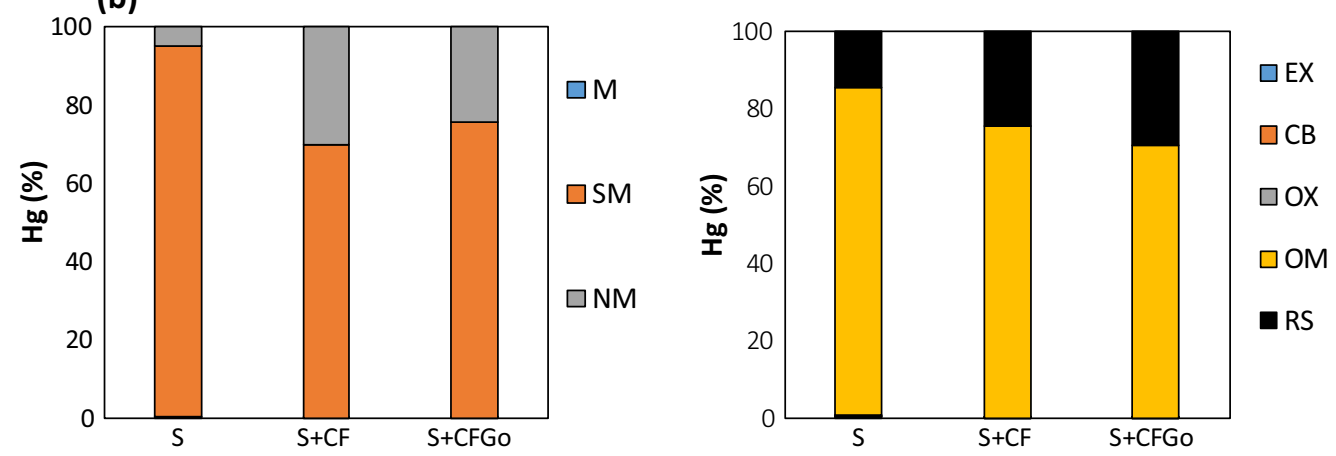

(c)
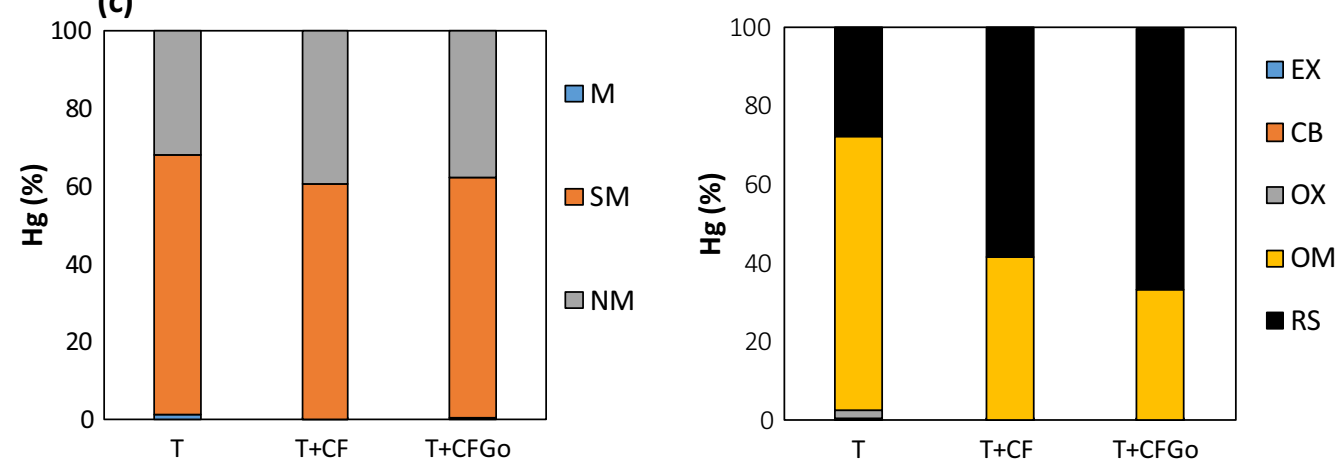

Fig. 4 Mercury fractionation following the USEPA method 3200 (M: mobile Hg, SM: semi-mobile Hg, NM: non-mobile Hg) (left column) and the Tessier method (EX: exchangeable Hg, CB: Hg bound to carbonates, OX: Hg bound to Fe-Mn oxides, OM: Hg bound to organic matter, RS: residual $\mathrm{Hg}$ ) (right column) in soils before and after treatment with the carbon foams for a A soil, b S soil and $\mathbf{c} T$ soil

thermal profiles in the soils after being treated with carbon foams (Fig. 3).

Similar conclusions were drawn from Tessier sequential extraction results (Fig. 4). A common pattern of $\mathrm{Hg}$ distribution was observed in the three soils after the treatment with the carbon foams, decreasing the mercury bound to organic matter, notably humic and fulvic acids (OM fraction), and increasing the mercury residual (RS fraction). The concentration of $\mathrm{Hg}$ in the non-available RS fraction was significantly increased after treatment with both carbon foams, especially in the case of $\mathrm{A}$ and $\mathrm{T}$ soils, reaching 80 and $65 \%$, respectively. Possible changes in $\mathrm{Hg}$ bonding during the extraction procedure cannot be ruled out, i.e., part of the $\mathrm{Hg}$ found in the residual fraction is in the form of $\mathrm{Hg}-\mathrm{HA}$ that was not extracted in the previous steps.

Although the duration of the leaching steps or the concentrations of the reagents would be taken into account, depending on the properties of the soil and the $\mathrm{Hg}$ content $[47,48]$, the results obtained by both methods and HgTPD procedure show good agreement for the untreated and treated soils. The presence of mercury complexed by humid acids identified by thermal desorption at $100-300^{\circ} \mathrm{C}$ was confirmed by the extraction of 
mercury from the SM and OM fractions. However, the presence of $\mathrm{HgS}$ in the soil treated with CFGo, which could be expected from the higher percentage of $\mathrm{Hg}$ found in the NM and RS fractions could not be confirmed by HgTPD. Nevertheless, the lower mobility of $\mathrm{Hg}$ after treatment with carbon foams (Fig. 2) was also confirmed by the higher concentration of $\mathrm{Hg}$ extracted in the NM and RS fractions and the thermal profiles that are wider and with a maximum desorption peak at slightly higher temperatures as a consequence of the change in the HA structure, which leads to a lower availability of Hg-HA species (Fig. 3).

\section{Impact on the $\mathrm{pH}$ and $\mathrm{EC}$ of soil and on Fe availability.}

To determine the impact of carbon foams on soil properties and compare it with the effects of nZVI, pH, EC and Fe concentration were measured (Figs. 2 and 5). As was previously mentioned, the application of nZVI hardly affected the $\mathrm{pH}$ of the soils with the exception of A soil, in which the $\mathrm{pH}$ increased. However, the treatment with the carbon foams led to a $\mathrm{pH}$ decrease, especially in the case of CF (Fig. 2). A lower pH enhances the immobilization of $\mathrm{Hg}$.

All the amendments increased soil EC values (Fig. 5), but $\mathrm{CF}$ induced the highest change, ranging from 0.2 , 0.4 and 0.1 to $1.9,2.9$ and $2.2 \mathrm{dS} \mathrm{m}^{-1}$ in $\mathrm{A}, \mathrm{S}$ and T soils, respectively. It is noteworthy that when $\mathrm{CF}$ is impregnated with goethite there is a more moderate increase in the EC values. This fact should be taken into account in relation to soil functionality and the possible damage to its biological activity and plant development.

When treatment impact on Fe availability was studied (Fig. 5), it was observed that the application of nZVI led to an increase in Fe leaching while the treatment with both carbon foams favored Fe immobility. The application of nZVI and the subsequent increase in Fe availability was found to be due to the diffusion of nZVI that are not retained in the soil, forming complexes with other elements [25]. However, the presence of certain surface groups in the foams could favor the decrease of available Fe [49]. It was observed that functional groups such as carboxylic and phenolic, which are negatively charged in a $\mathrm{pH}$ range of 4 to 8 and were identified in the carbon foams by TPD (Additional file 1: Figure S2), can bind metal cations strongly [50].

\section{Conclusions}

A novel carbon foam-based amendment was efficient in immobilizing $\mathrm{Hg}$ in all the soils studied. The methods used in this study allowed estimating the main form of $\mathrm{Hg}$ binding in the studied soils. The main species present in soils were $\mathrm{HgS}$ and $\mathrm{Hg}-\mathrm{HA}$, the latter being the one that
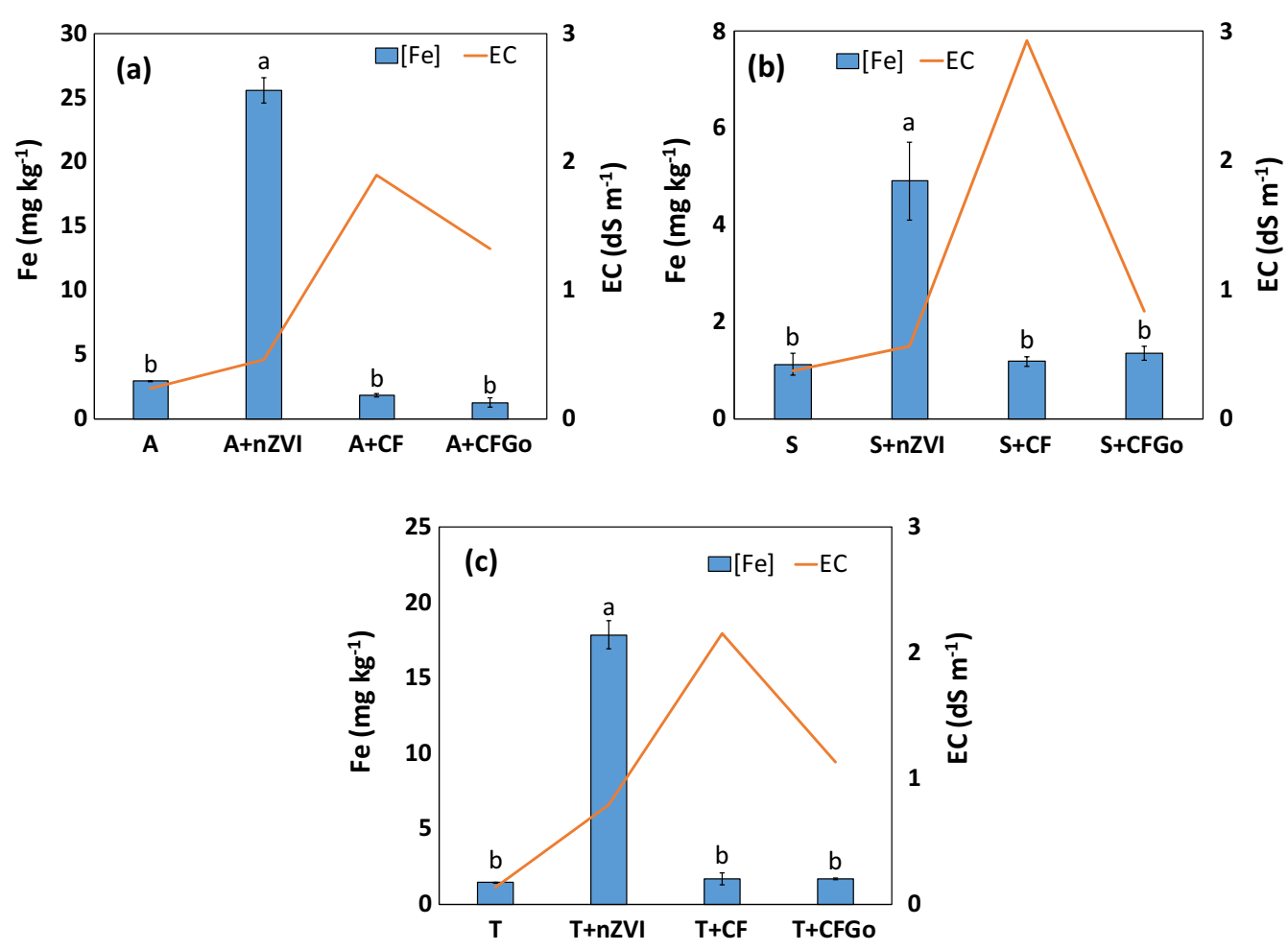

Fig. 5 Iron concentration and EC value in TCLP extracts after application of the three treatments to $\mathbf{a} A$ soil, $\mathbf{b} S$ soil and $\mathbf{c} T$ soil 
determined the percentage of mobility and availability of $\mathrm{Hg}$ when soils were treated with the carbon foams. When the $\mathrm{pH}$ dropped, the structure of humic acid changed causing the $\mathrm{Hg}-\mathrm{HA}$ species to become part of the unavailable fraction of the soil along with $\mathrm{HgS}$. The carbon foam impregnated with goethite, in addition to not mobilizing $\mathrm{Fe}$, presented the additional advantage of its lesser effect on the soil electrical conductivity. Furthermore, this type of amendment could also be used for the remediation of soils of similar characteristics (neutral or slightly alkaline), mainly from industrial and abandoned mining areas, contaminated with other metal(loid)s.

\begin{abstract}
Abbreviations
AMA: Advanced Mercury Analyzer; ${ }^{\circ} \mathrm{C}$ : Celsius degrees; CB: Fraction bound to carbonates; CSIC: Consejo Superior de Investigaciones Científicas. (Spanish National Research Council); DL: Detection limit; dS: DeciSiemens; EC: Electrical conductivity; EX: Fraction exchangeable; EXAFS: Extended X-ray absorption fine structure; g: Grams; h: Hour; $\mathrm{Hg}^{0}$ : Elemental gaseous mercury; $\mathrm{Hg}^{2+}$ : Oxidized mercury; HA: Humic acid; HgTPD: Mercury temperature programmed desorption; INDUROT: Institute of Natural Resources and Territoral Planning (University of Oviedo); kg: Kilogram; kHz: Kilohertz; L: Liter; $\mu g$ : Microgram; m: Meter; M: Mobile; mg: Milligram; min: Minutes; $\mathrm{mL}$ : Milliliter; mm: Millimeter; NBS: Natural-based solutions; NM: No mobile; nZVI: Zero valence iron nanoparticles; OM: Fraction bound to organic matter; OX: Fraction bound to Fe and Mn oxides; rpm: Revolutions per minute; RS: Residual fraction; SEM: Scanning electron microscope; SM: Semi-mobile; T: Temperature; TPD: Temperature programmed desorption; TCLP: Toxicity characterization leaching procedure; UNEP: United Nations Environmental Program; USEPA: United States Environmental Protection Agency; V: Volt; \% w/w: Weigh percentage; XANES: X-ray absorption near edge structure; XRD: X-ray diffraction.
\end{abstract}

\section{Supplementary Information}

The online version contains supplementary material available at https://doi. org/10.1186/s12302-021-00569-w.

Additional file 1: Table S1. General and textural properties of the carbon foams. Figure S1. XRD pattern of the carbon foam impregnated with goethite (CFGo). The major peaks at $2 \Theta$ values of $20.8^{\circ}, 33.2^{\circ}, 35.6^{\circ}, 36.7^{\circ}$, $54^{\circ}$ and $59.2^{\circ}$ are assigned to the primary peaks of the goethite $(\mathrm{FeO}(\mathrm{OH}))$. The wider band between 20 and $30^{\circ}$ corresponds to disordered carbon. The mineral matter of carbon foam is reflected by the peak at $26^{\circ}(\mathrm{SiO} 2)$. Figure S2. TPD profiles of CO and CO2 evolution in (a) CF and (b) CFGo. Figure S3. Deconvolution carried out with the Origin program for mercury thermal profiles of untreated and treated A, S and T soils.

\section{Acknowledgements}

We acknowledge support of the publication fee by the CSIC Open Access Publication Support Initiative through its Unit of Information Resources for Research (URICI).

\section{Authors' contributions}

IJ-T: conceptualization, investigation. MAL-A: writing (original draft) (review and editing), supervision, project administration. DB: resources, statistical analysis and interpretation. CA-N: investigation. ER: investigation. AIP: writing (review and editing), supervision. JRG: writing (review and editing), funding acquisition. MRM-T writing (review and editing), funding acquisition.

\section{Funding}

The study was part of the JAE-Intro fellowship awarded to Iria Janeiro Tato (Ref.: JAEICU-19-INCAR-9) funded by CSIC and the projects MCI-20PID2019-106939 GB-I00 and PID2020-1 13558RB-C43 funded by AEI/Spain, FEDER/EU.

\section{Availability of data and materials}

The datasets used and/or analyzed during the current study are available from the corresponding author on reasonable request.

\section{Declarations}

Ethics approval and consent to participate

Not applicable.

\section{Consent for publication}

Not applicable.

\section{Competing interests}

The authors declare that they have no competing interests.

\section{Author details}

${ }^{1}$ Instituto de Ciencia Y Tecnología del Carbono, INCAR-CSIC, C/ Francisco Pintado Fe, 26, 33011 Oviedo, Spain. ${ }^{2}$ INDUROT and Environmental Biogeochemistry and Raw Materials Group, University of Oviedo, Mieres, Spain. ${ }^{3}$ Area of Microbiology, Department of Functional Biology and Environmental Biogeochemistry and Raw Materials Group, University of Oviedo, Oviedo, Spain. ${ }^{4}$ Institute of Biotechnology of Asturias (IUBA), University, University of Oviedo, Oviedo, Spain.

Received: 19 Auqust 2021 Accepted: 23 October 2021

Published online: 13 November 2021

References

1. UNEP (2017) United Nations Environment Programme, 2017. Minamata Convention on Mercury, 2017.

2. UNEP (2018) Global Mercury Assessment 2018 / UNEP - UN Environment Programme. https://www.unep.org/resources/publication/global-mercu ry-assessment-2018. Accessed 26 Apr 2021

3. Tangahu BV, Sheikh Abdullah SR, Basri H, et al (2011) A review on heavy metals ( $\mathrm{As}, \mathrm{Pb}$, and $\mathrm{Hg}$ ) uptake by plants through phytoremediation. Int. J. Chem. Eng.

4. Wang J, Feng X, Anderson CWN et al (2012) Remediation of mercury contaminated sites-a review. J Hazard Mater 221-222:1-18

5. Xu J, Bravo AG, Lagerkvist A et al (2015) Sources and remediation techniques for mercury contaminated soil. Environ Int 74:42-53

6. Baragaño D, Forján R, Sierra C, Gallego JLR (2021) Nanomaterials for soil remediation: pollutant immobilization and opportunities for hybrid technologies. Sorbents Mater Control Environ Pollut. https://doi.org/10. 1016/B978-0-12-820042-1.00026-2

7. Richter RB, Flachberger H (2010) Soil washing and thermal desorption: reliable techniques for remediating materials contaminated with Mercury Bodenwäsche und thermische Desorption: zuverlässige Technologien zur Aufbereitung quecksilberkontaminierter Böden. BHM Berg- Huettenmaenn Monatsh 155:571-577. https://doi.org/10.1007/ s00501-010-0617-0

8. Song Y, Kirkwood N, Maksimović Č et al (2019) Nature based solutions for contaminated land remediation and brownfield redevelopment in cities: a review. Sci Total Environ. https://doi.org/10.1016/j.scitotenv.2019.01.347

9. Ma F, Peng C, Hou D et al (2015) Citric acid facilitated thermal treatment: an innovative method for the remediation of mercury contaminated soil. J Hazard Mater 300:546-552. https://doi.org/10.1016/j.jhazmat.2015.07. 055 
10. Mahbub KR, Krishnan K, Andrews S et al (2017) Bio-augmentation and nutrient amendment decrease concentration of mercury in contaminated soil. Sci Total Environ 576:303-309. https://doi.org/10.1016/j.scito tenv.2016.10.083

11. Gil-Díaz M, Alonso J, Rodríguez-Valdés E et al (2017) Comparing different commercial zero valent iron nanoparticles to immobilize As and $\mathrm{Hg}$ in brownfield soil. Sci Total Environ. https://doi.org/10.1016/j.scitotenv.2017. 02.011

12. Blom M (2012) Summary report mercury contaminated sites Brussels, Belgium Event hosted by Solvay Report compiled by Marianne Blom, Environ Report on the NICOLE Technical Meeting: Mercury Contaminated Sites

13. Huang Y, Wang M, Li Z et al (2019) In situ remediation of mercurycontaminated soil using thiol-functionalized graphene oxide/Fe-Mn composite. J Hazard Mater 373:783-790. https://doi.org/10.1016/j.jhazm at.2019.03.132

14. O'Connor D, Peng T, Li G et al (2018) Sulfur-modified rice husk biochar: a green method for the remediation of mercury contaminated soil. Sci Total Environ 621:819-826. https://doi.org/10.1016/j.scitotenv.2017.11. 213

15. Xiong Z, He F, Zhao D, Barnett MO (2009) Immobilization of mercury in sediment using stabilized iron sulfide nanoparticles. Water Res 43:5171-5179. https://doi.org/10.1016/j.watres.2009.08.018

16. Wang X, Wang S, Pan X, Gadd GM (2019) Heteroaggregation of soil particulate organic matter and biogenic selenium nanoparticles for remediation of elemental mercury contamination. Chemosphere 221:486-492. https://doi.org/10.1016/j.chemosphere.2019.01.073

17. Lefevre E, Bossa N, Wiesner MR, Gunsch CK (2015) A review of the environmental implications of in situ remediation by nanoscale zero valent iron (nZVI): Behavior, transport and impacts on microbial communities. Sci Total Environ 565:889-901. https://doi.org/10.1016/j.scitotenv.2016.02. 003

18. Derakhshan Nejad Z, Jung MC, Kim KH (2018) Remediation of soils contaminated with heavy metals with an emphasis on immobilization technology. Environ Geochem Health 40:927-953

19. Wang L, Hou D, Cao Y et al (2020) Remediation of mercury contaminated soil, water, and air: a review of emerging materials and innovative technologies. Environ Int 134:105281

20. Issaro N, Abi-Ghanem C, Bermond A (2009) Fractionation studies of mercury in soils and sediments: a review of the chemical reagents used for mercury extraction. Anal Chim Acta 631:1-12

21. Huggins FE, Yap N, Huffman GP, Senior CL (2003) XAFS characterization of mercury captured from combustion gases on sorbents at low temperatures. Fuel Process Technol 82:167-196. https://doi.org/10.1016/ S0378-3820(03)00068-7

22. Reis AT, Coelho JP, Rodrigues SM et al (2012) Development and validation of a simple thermo-desorption technique for mercury speciation in soils and sediments. Talanta 99:363-368. https://doi.org/10.1016/j.talanta. 2012.05.065

23. Nagel B, Pusz S, Trzebicka B (2014) Review: tailoring the properties of macroporous carbon foams. J Mater Sci 49:1-17

24. Harter RD, Naidu R (1995) Role of metal-organic complexation in metal sorption by soils. Adv Agron 55:219-263. https://doi.org/10.1016/S00652113(08)60541-6

25. Baragaño D, Alonso J, Gallego JR et al (2020) Zero valent iron and goethite nanoparticles as new promising remediation techniques for As-polluted soils. Chemosphere. https://doi.org/10.1016/j.chemosphere. 2019.124624

26. Matanzas N, Sierra MJ, Afif E et al (2017) Geochemical study of a miningmetallurgy site polluted with $\mathrm{As}$ and $\mathrm{Hg}$ and the transfer of these contaminants to Equisetum sp. J Geochemical Explor 182:1-9. https:// doi.org/10.1016/j.gexplo.2017.08.008

27. Gallego JR, Esquinas N, Rodríguez-Valdés E et al (2015) Comprehensive waste characterization and organic pollution co-occurrence in a $\mathrm{Hg}$ and As mining and metallurgy brownfield. J Hazard Mater. https://doi.org/10. 1016/j.jhazmat.2015.07.029
28. Baragaño B, Ratié R, Sierra C et al (2021) Multiple pollution sources unravelled by environmental forensics techniques and multivariate statistics. J Hazard Mater. https://doi.org/10.1016/J.JHAZMAT.2021.127413

29. Rodríguez E, García R (2012) Microporosity development in coal-based carbon foams. Energy Fuels 26:3703-3710. https://doi.org/10.1021/ef300 $193 c$

30. Figueiredo JL, Pereira MFR, Freitas MMA, Órfão JJM (1999) Modification of the surface chemistry of activated carbons. Carbon N Y 37:1379-1389. https://doi.org/10.1016/S0008-6223(98)00333-9

31. Szymański GS, Karpiński Z, Biniak S, Świątkowski A (2002) The effect of the gradual thermal decomposition of surface oxygen species on the chemical and catalytic properties of oxidized activated carbon. Carbon N Y 40:2627-2639. https://doi.org/10.1016/S0008-6223(02)00188-4

32. Baragaño D, Forján R, Fernández B et al (2020) Application of biochar, compost and ZVI nanoparticles for the remediation of $\mathrm{As}, \mathrm{Cu}, \mathrm{Pb}$ and Zn polluted soil. Environ Sci Pollut Res. https://doi.org/10.1007/ s11356-020-09586-3

33. Tessier A, Campbell PGC, Bisson M (1979) Sequential extraction procedure for the speciation of particulate trace metals. Anal Chem 51:844-851. https://doi.org/10.1021/ac50043a017

34. USEPA (2014) Method 3200: Mercury Species Fractionation and Quantification by Microwave Assisted Extraction, Selective Solvent Extraction and/or Solid Phase Extraction. moz-extension://09095646-0d3d433f-8839-0c59dfcfb1ad/enhanced-reader.html?openApp\&pdf=http s\%3A\%2F\%2Fwww.epa.gov\%2Fsites\%2Fproduction\%2Ffiles\%2F201512\%2Fdocuments\%2F3200.pdf. Accessed 26 Mar 2021

35. Rumayor M, Lopez-Anton MA, Diaz-Somoano M, Martinez-Tarazona MR (2015) Device for identification of mercury species in solids No Title

36. Gallego JLR, López-Antón MA, de la Rosa DM et al (2019) Assessment of mercury pollution sources in beach sand and coastal soil by speciation analysis. Environ Sci Eur. https://doi.org/10.1186/s12302-019-0264-3

37. BOPA (2014) Boletín Oficial del Principado de Asturias. Generic reference levels for heavy metals in soils from Principality of Asturias, Spain, 2014. http://sede.asturias.es/bopa/2014/04/21/2014-06617.pdf

38. Crommentuijn T, Sijm D, De Bruijn J et al (2000) Maximum permissible and negligible concentrations for metals and metalloids in the Netherlands, taking into account background concentrations. J Environ Manage 60:121-143. https://doi.org/10.1006/jema.2000.0354

39. MEF (2007) Ministry of Environment Finland. Government Decree on the Assessment of soil contamination and remediation needs 214/2007, March 1

40. Yang Y, kui, Zhang C, Shi X jun, et al (2007) Effect of organic matter and $\mathrm{pH}$ on mercury release from soils. J Environ Sci 19:1349-1354. https://doi. org/10.1016/S1001-0742(07)60220-4

41. Klučáková M (2018) Size and charge evaluation of standard humic and fulvic acids as crucial factors to determine their environmental behavior and impact. Front Chem 6:235. https://doi.org/10.3389/fchem.2018. 00235

42. Gil-Díaz M, Rodríguez-Valdés E, Alonso J et al (2019) Nanoremediation and long-term monitoring of brownfield soil highly polluted with As and Hg. Sci Total Environ. https://doi.org/10.1016/j.scitotenv.2019.04.183

43. Johs A, Eller VA, Mehlhorn TL et al (2019) Dissolved organic matter reduces the effectiveness of sorbents for mercury removal. Sci Total Environ 690:410-416. https://doi.org/10.1016/J.SCITOTENV.2019.07.001

44. Chen C, Ting Y, Ch'ng B-L, Hsi H-C (2020) Influence of sulfide, chloride and dissolved organic matter on mercury adsorption by activated carbon in aqueous system. Sustain Environ Res 301(30):1-15. https://doi.org/10. 1186/S42834-020-00065-5

45. Durce D, Maes N, Bruggeman C, Van Ravestyn L (2016) Alteration of the molecular-size-distribution of Boom Clay dissolved organic matter induced by $\mathrm{Na}+$ and Ca2 +. J Contam Hydrol 185-186:14-27. https://doi. org/10.1016/j.jconhyd.2015.12.001

46. Nirel PMV, Morel FMM (1990) Pitfalls of sequential extractions. Water Res 24:1055-1056. https://doi.org/10.1016/0043-1354(90)90129-T 
47. Biester H, Müller G, Schöler HF (2002) Binding and mobility of mercury in soils contaminated by emissions from chlor-alkali plants. Sci Total Environ 284:191-203. https://doi.org/10.1016/S0048-9697(01)00885-3

48. Biester H, Scholz C (1997) Determination of mercury binding forms in contaminated soils: mercury pyrolysis versus sequential extractions. Environ Sci Technol 31:233-239. https://doi.org/10.1021/ES960369H

49. Park JH, Lamb D, Paneerselvam P et al (2011) Role of organic amendments on enhanced bioremediation of heavy metal(loid) contaminated soils. J Hazard Mater 185:549-574
50. Abou Jaoude L, Garau G, Nassif N et al (2019) Metal(loid)s immobilization in soils of Lebanon using municipal solid waste compost: Microbial and biochemical impact. Appl Soil Ecol 143:134-143. https://doi.org/10. 1016/j.apsoil.2019.06.011

\section{Publisher's Note}

Springer Nature remains neutral with regard to jurisdictional claims in published maps and institutional affiliations.

\section{Submit your manuscript to a SpringerOpen ${ }^{\circ}$ journal and benefit from:}

- Convenient online submission

- Rigorous peer review

- Open access: articles freely available online

- High visibility within the field

- Retaining the copyright to your article

Submit your next manuscript at $\boldsymbol{\nabla}$ springeropen.com 